\title{
Correction to: Four aspects of building robotic systems: lessons from the Amazon Picking Challenge 2015
}

Clemens Eppner $^{1} \cdot$ Sebastian Höfer ${ }^{1}$ (D) Rico Jonschkowski ${ }^{1} \cdot$ Roberto Martín-Martín $^{1} \cdot$ Arne Sieverling $^{1}$ (i) $\cdot$ Vincent Wall ${ }^{1}$. Oliver Brock ${ }^{1}$ (D)

Published online: 21 November 2020

๑) Springer Science+Business Media, LLC, part of Springer Nature 2020

\section{Correction to:}

Autonomous Robots (2018) 42:1459-1475 https://doi.org/10.1007/s10514-018-9761-2

Publisher's Note Springer Nature remains neutral with regard to jurisdictional claims in published maps and institutional affiliations.

In the original publication of the article, the incorrect author photo was displayed in biography section. The author Clemens Eppner regrets the inclusion of the incorrect author photo in the article. The correct photo is given below:

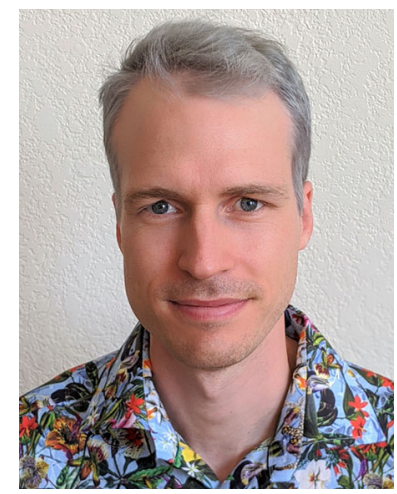

The original article can be found online at https://doi.org/10.1007/ s10514-018-9761-2.

$\triangle$ Arne Sieverling arne.sieverling@tu-berlin.de

1 Robotics and Biology Laboratory, Fakultät IV, MAR 5-1, Marchstr. 23, 10587 Berlin, Germany 